\title{
Global Economic Changes and the Commodification of Human Capital: Implications of Filipino Nurse Migration
}

\section{Angelo Salting Goode}

Published online: 29 April 2009

(C) Springer Science + Business Media B.V. 2009

\section{Erratum to: East Asia \\ DOI 10.1007/s12140-009-9074-3}

Due to a technical error, the Acknowledgements and the biography of the author have been left out the published article.

Below you will find that information.

Acknowledgements To my beloved parents, Maria Theresa Ranin Salting and Anthony John Newnham. Thank you also to my Supervisor, for his encouragement, support and inspiration. The author would like to thank the comments from the three anonymous reviewers of East Asia.

Angelo Salting Goode is an Assistant Professor in Political Science at De La Salle University, Manila. He received his BA in Diplomacy and World Affairs (emphasis comparative politics and development) from Occidental College, Los Angeles and his MA in International Relations (focus East Asia) from Durham University, England-where Angelo is also a $\mathrm{PhD}$ Candidate in Politics. His current research interests examine the Philippines as one of the world's greatest exporters of migrant workers, and how it adjusts to its new-found position in the 21 st Century global economy. Future research interests explore the Middle East, particularly Iran's engagement with East Asia.

The online version of the original article can be found under http://dx.doi.org/10.1007/s12140-009-9074-3.

A. Salting Goode $(\bowtie)$

International Studies Department, De La Salle University Manila, \#2401 Taft Avenue,

Metro Manila 1004, Philippines

e-mail: angelo.goode@gmail.com 